\title{
Neochordal repair of the posterior mitral leaflet
}

\author{
John J. Nigro, MDa \\ Daniel S. Schwartz, MD \\ Robert D. Bart, MD ${ }^{\mathrm{a}}$ \\ Candace W. Bart, $\mathrm{RN}^{\mathrm{a}}$ \\ Becky M. Lopez, RN \\ Mark J. Cunningham, MD \\ Mark L. Barr, MD ${ }^{\mathrm{a}}$ \\ Ross M. Bremner, MD, PhD ${ }^{\mathrm{a}}$ \\ Steven M. Haddy, MD ${ }^{b}$ \\ Winfield J. Wells, MD ${ }^{a}$ \\ Vaughn A. Starnes, MD ${ }^{a}$
}

\footnotetext{
From the Departments of Cardiothoracic Surgery $^{\mathrm{a}}$ and Anesthesiology, ${ }^{\mathrm{b}}$ Keck School of Medicine of the University of Southern California, Los Angeles, Calif.

Read at the Twenty-ninth Annual Meeting of The Western Thoracic Surgical Association, Carlsbad, Calif, June 18-21, 2003.

Received for publication June 18, 2003; revisions requested Aug 26, 2003; revisions received Sept 9, 2003; accepted for publication Oct 7, 2003.

Address for reprints: John J. Nigro, MD, Children's Hospital Los Angeles, Department of Cardiothoracic Surgery, 4650 Sunset Blvd, MS 66, Los Angeles, CA 90027 (E-mail: jnigro@chla.usc.edu).

J Thorac Cardiovasc Surg 2004;127:440-7

0022-5223/\$30.00

Copyright (C) 2004 by The American Association for Thoracic Surgery

doi:10.1016/j.jtcvs.2003.09.035
}

\begin{abstract}
Background: Myxomatous mitral valve insufficiency is traditionally repaired by posterior leaflet quadrangular resection and reconstruction. A simplified repair technique without leaflet resection is described, and our initial experience is reviewed.
\end{abstract}

Methods: Thirty-nine consecutive patients with significant mitral regurgitation underwent repair since January 2000 by placement of expanded polytetrafluoroethylene sutures between the leading (coapting) edge of the posterior leaflet and the corresponding papillary muscle. An annuloplasty ring was placed, and no leaflet tissue was resected. Patient medical records were obtained and retrospectively reviewed.

Results: Twenty-five men and 14 women (median age, 61 years; range, 40-88 years) had their mitral valve repaired by a variety of surgical approaches, including robotic (18 patients), right thoracotomy (6 patients), and sternal (15 patients). Three patients have required valve replacement: 1 at the initial operation, 1 because of dehiscence of the annuloplasty ring, and 1 after subsequent rupture of a previously normal native chorda. At follow-up (median, 12 months), 92\% (33/36) of the remaining patients had an intact mitral repair with no to mild regurgitation, $8.3 \%(3 / 36)$ of patients had moderate regurgitation, and $92 \%$ of all patients (36/39) were in New York Heart Association class I. There were no deaths.

Conclusions: Myxomatous mitral regurgitation due to posterior leaflet insufficiency can be repaired without leaflet resection by placement of neochordae. This repair technique is effective and is readily accomplished by traditional and minimally invasive surgical approaches.

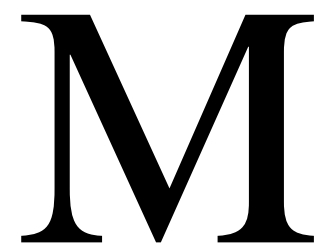

yxomatous degeneration of the mitral valve is the most common etiology of surgically significant mitral regurgitation for adults in the United States and other developed countries. ${ }^{1-4}$ This type of valve failure is often due to prolapse or flail of the middle scallop of the posterior mitral leaflet. ${ }^{1,2}$ Mitral valve repair has proven to be an effective, safe, and durable means to treat this lesion. ${ }^{3-20}$ Repair is traditionally accomplished by quadrangular resection of the prolapsed or flail posterior leaflet segment with reconstruction of the leaflet and placement of an annuloplasty ring. ${ }^{5-8,15}$

Recent reports suggest that similar results can be obtained without removal of leaflet tissue by using expanded polytetrafluoroethylene (ePTFE) suture neochordae 

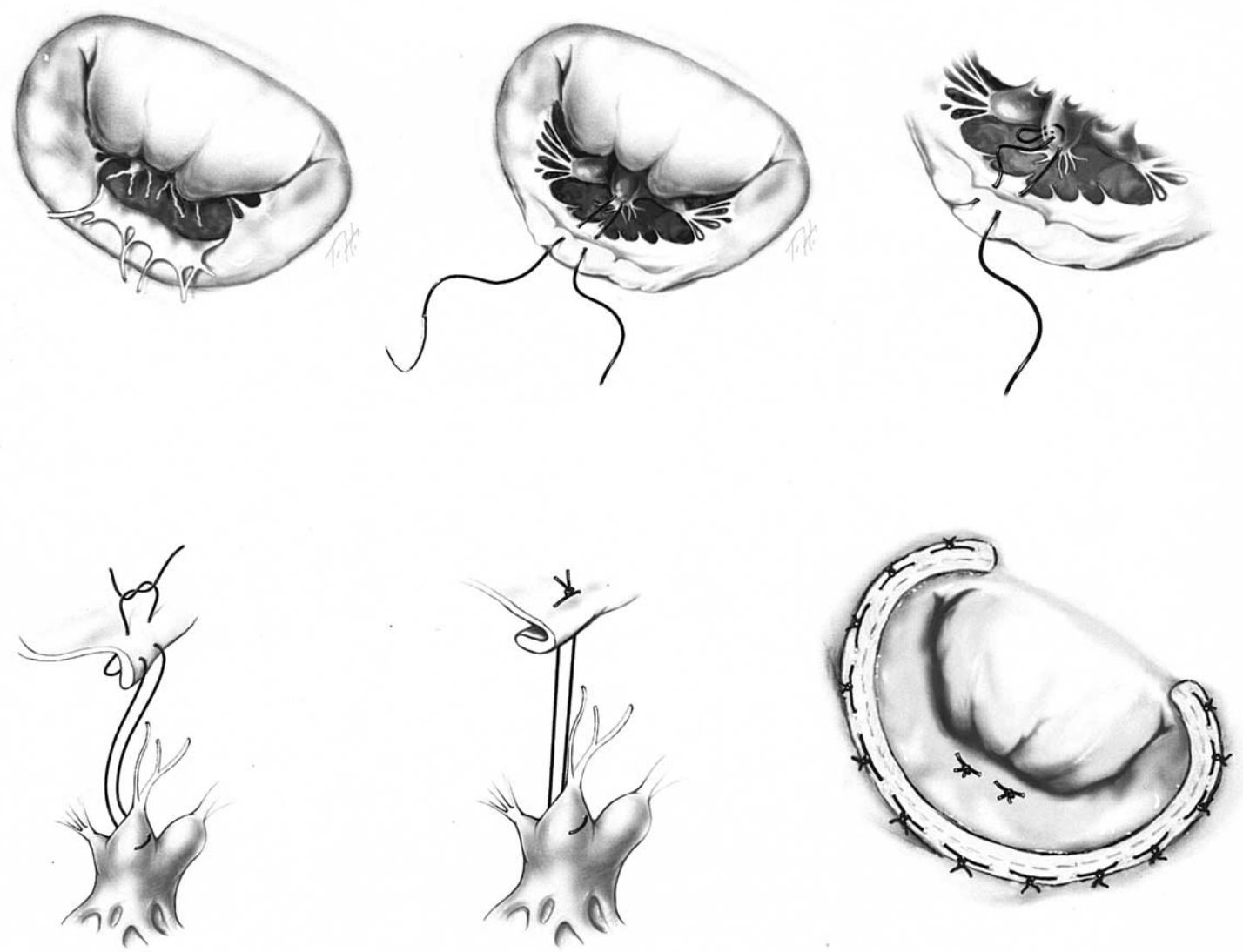

Figure 1. Demonstration of placement of ePTFE neochordae, and the completed repair with an annuloplasty ring.

to resuspend the prolapsed or flail portion of the leaflet. ${ }^{4,21,22}$ This technique allows conservation of valve (leaflet) tissue and can be readily implemented via open, minimally invasive, and robotic approaches. We have used this technique to repair mitral regurgitation due to posterior leaflet prolapse since January 2000 and believe that it is an effective repair alternative to leaflet resection (quadrangular). A description of the technique and our experience with this valve repair method are reviewed.

\section{Materials and Methods}

This study was approved by the University of Southern California Institutional Review Board.

\section{Patient Demographics}

This is a review of our first 39 consecutive adult patients to undergo repair for mitral valve regurgitation with neochordal resuspension of the posterior mitral leaflet. It includes a retrospective review of each patient's medical record. All procedures were performed by a single surgeon (V.A.S.) between January 2000 and May 2003. All patients had significant mitral regurgitation (moderate to severe) due to prolapse of the posterior mitral leaflet. Bileaflet prolapse was present in 3 patients.

\section{Preoperative Assessment}

Patients had a preoperative evaluation and a transthoracic echocardiogram. A cardiac catheterization was performed in 38 patients to define concomitant coronary artery pathology. Preoperative New York Heart Association (NYHA) classification was determined on the basis of individual medical records.

\section{Surgical Technique}

Intraoperative transesophageal echocardiogram was performed on each patient before the initiation of cardiopulmonary bypass. Perioperative transesophageal echocardiograms were performed during hemodynamic stability and with normal volume and pressure loading. Mitral valve repair was performed by median sternotomy, a minimally invasive (right thoracotomy) approach, or a robotically assisted approach. All procedures were performed with hypothermia $\left(28^{\circ} \mathrm{C}-32^{\circ} \mathrm{C}\right)$ and cold blood cardioplegic hyperkalemic cardiac arrest. The valve was directly inspected and tested, and the mode of valve failure was determined. Posterior leaflet prolapse was identified by the presence of ruptured or elongated chordae. A single-armed 4-0 ePTFE suture was passed from the left atrium through the prolapsed leaflet segment and back (through the leaflet) to the atrial side. The suture entered leaflet tissue approximately $0.5 \mathrm{~cm}$ from the free edge at the junction between the rough and smooth portions of the leaflet, and it exited (the 


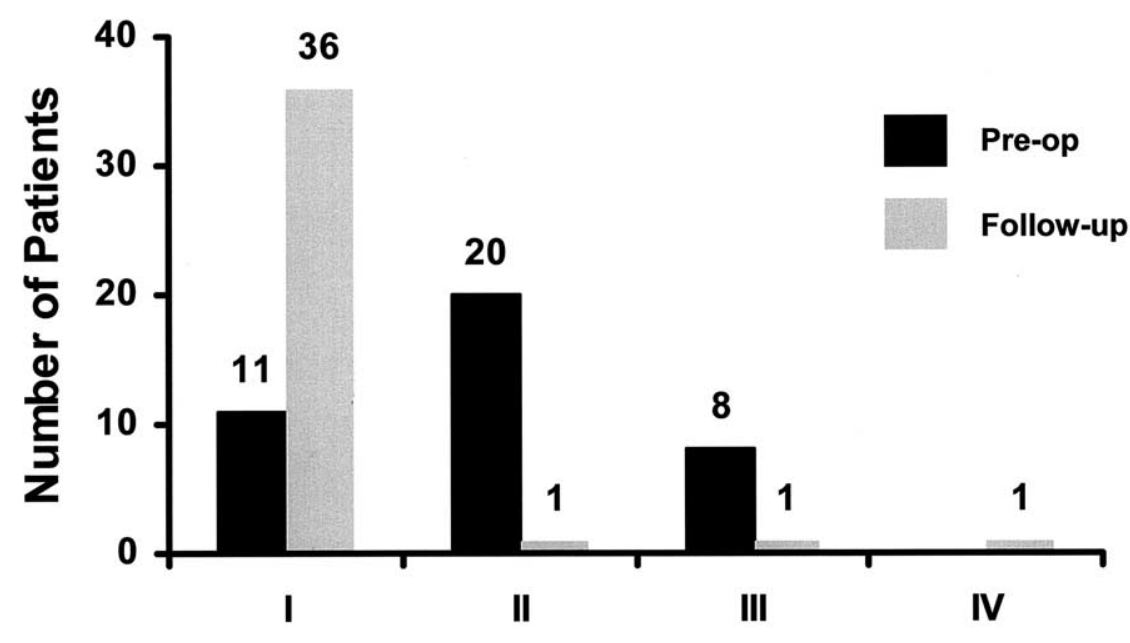

New York Heart Association Classification

Figure 2. New York Heart Association classification for patients before surgery and at follow-up.

leaflet atrial surface) near its free edge (Figure 1). The suture was then brought through a secure area in the corresponding papillary muscle and back through the leaflet (Figure 1). Once tied, the knot was on the atrial side of the leaflet. Neochorda length was adjusted on the basis of the length of adjacent normal chordae to provide optimal leaflet coaptation. The valve was tested, and additional sutures were placed as needed to recreate valvular competence. A flexible annuloplasty ring (Cosgrove-Edwards Annuloplasty System; Edwards Lifesciences, Irvine, Calif) was sized on the basis of the anterior leaflet and then secured with interrupted sutures. A postrepair transesophageal echocardiogram was performed after separation from bypass. All patients received at least 6 weeks of anticoagulation therapy with warfarin sodium (Coumadin).

\section{Follow-up}

All patients were contacted, underwent transthoracic echocardiography, and were interviewed between March and June of 2003. Follow-up was complete in all patients at a median of 12 months (range, 0.5-38 months). An NYHA classification was determined on the basis of the follow-up interview.

\section{Echocardiogram}

All preoperative and follow-up transthoracic echocardiograms were completed via standard acoustic windows by using M-mode, 2-dimensional, and Doppler color flow modalities. Regurgitation was graded by the amount of Doppler-measured turbulence in the left atrium according to accepted criteria ${ }^{19}$ and was categorized as zero to mild, moderate, and severe.

\section{Statistical Analysis}

Descriptive statistics were used to describe group characteristics and results.

\section{Results \\ Population}

There were 25 men and 14 women, with a median age of 61 years (range, 40-88 years). Fifteen percent of the patients (6/39) were asymptomatic with known mitral valve prolapse and significant mitral regurgitation on echocardiogram. The most common symptom was shortness of breath, which was present in $26(67 \%)$ of 39 patients. One patient presented with angina due to significant coronary artery disease. Preoperative NYHA classification for the patients is presented in Figure 2. Surgically significant coronary artery disease was present in $10 \%$ of the patients (4/39). One patient had prior coronary revascularization. Preoperative echocardiogram demonstrated severe $(4+)$ mitral regurgitation in $67 \%$ $(26 / 39)$ and moderate $(3+)$ mitral regurgitation in the rest (33\%; 13/39; Figure 3).

\section{Procedure}

Forty-six percent of the patients (18/39) had their mitral valve repair completed robotically, 39\% (15/39) had repair via a median sternotomy, and the remaining $15 \%(6 / 39)$ had a minimally invasive (right thoracotomy) surgical approach (Figure 4). Two patients were converted from a roboticassisted to an open or right thoracotomy approach. At operation, all patients had prolapse of the posterior mitral leaflet, and 3 had both leaflets involved. Complete flail due to ruptured chordae was present in 21 (54\%) patients. The middle scallop of the posterior leaflet was the only (leaflet) segment to be prolapsed in $26(67 \%)$ patients. Concomitant procedures were performed in $21 \%$ (8/39) of the patients and included coronary revascularization $(n=4)$, modified 


\section{Surgical Approach}

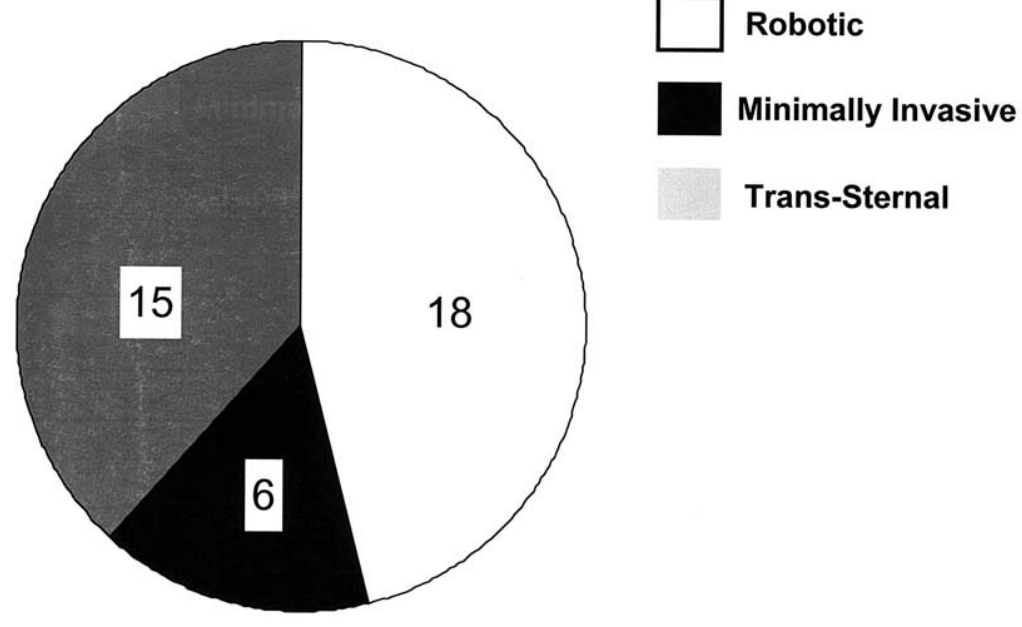

Figure 3. The surgical approach used to complete mitral valve repair.

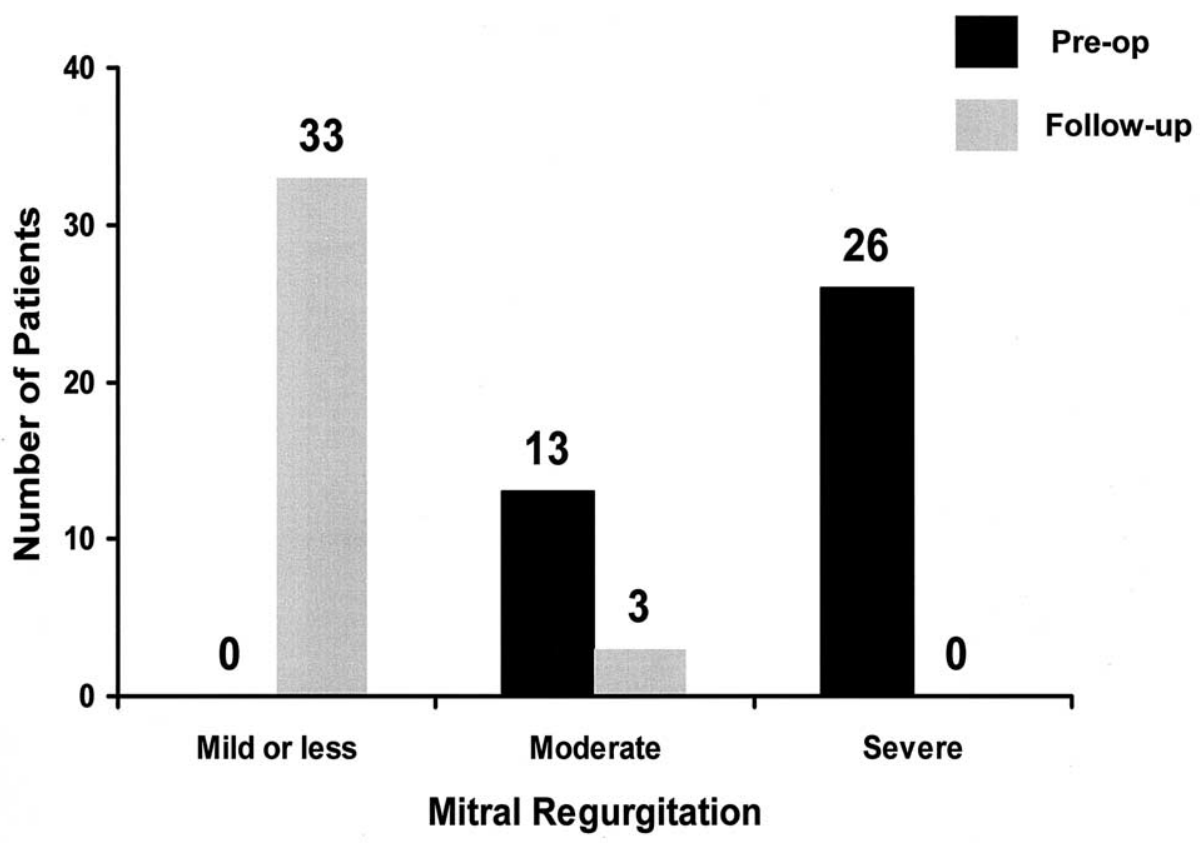

Figure 4. Presentation of echocardiographic grading of mitral regurgitation for patients before surgery and at follow-up. The 3 patients with mitral valve replacement are not included in the follow-up group.

maze $(\mathrm{n}=3)$, and aortic valve replacement $(\mathrm{n}=1)$. Perfusion and cross-clamp times for the entire group and by surgical approach are listed in Table 1. Each ePTFE suture placed formed 2 neochordae (Figure 1). Annuloplasty ring size, number of sutures, and number of neochordae are listed in Table 2.

\section{Mortality and Morbidity}

There were no operative deaths, and all patients are alive at follow-up (June 2003). Re-exploration for bleeding was performed in 4 patients. Postoperative atrial fibrillation or supraventricular tachycardia occurred in 10 patients. Pacemakers were placed in 3 patients, and an automatic implant- 
TABLE 1. Perfusion and crossclamp times

\begin{tabular}{|c|c|c|c|c|c|c|c|c|}
\hline \multirow[b]{2}{*}{ Variable } & \multicolumn{2}{|c|}{ All patients $(n=39)$} & \multicolumn{2}{|c|}{ Robotic (n=18) } & \multicolumn{2}{|c|}{ Minimally invasive $(n=15)$} & \multicolumn{2}{|c|}{ Transsternal $(n=6)$} \\
\hline & Perfusion & Crossclamp & Perfusion & Crossclamp & Perfusion & Crossclamp & Perfusion & Crossclamp \\
\hline $\begin{array}{l}\text { Mean } \pm \text { SD (min) } \\
\text { Median (min) } \\
\text { Ranqe (min) }\end{array}$ & $\begin{array}{c}100 \pm 39 \\
99 \\
39-183\end{array}$ & $\begin{array}{c}71 \pm 30 \\
66 \\
24-142\end{array}$ & $\begin{array}{c}130 \pm 25 \\
123 \\
83-183\end{array}$ & $\begin{array}{c}93 \pm 19 \\
87 \\
63-138\end{array}$ & $\begin{array}{c}92 \pm 46 \\
89 \\
39-170\end{array}$ & $\begin{array}{c}61 \pm 43 \\
52 \\
24-142\end{array}$ & $\begin{array}{c}67 \pm 15 \\
64 \\
45-79\end{array}$ & $\begin{array}{c}48 \pm 14 \\
50 \\
28-79\end{array}$ \\
\hline
\end{tabular}

TABLE 2. Operative data

\begin{tabular}{lccc}
\hline Variable & No. sutures & Neochordae & $\begin{array}{c}\text { Annuloplasty } \\
\text { ring size }\end{array}$ \\
\hline Median & 2 & 4 & 30 \\
Mode & 1 & 2 & 30 \\
Range & $1-4$ & $2-8$ & $26-34$ \\
\hline
\end{tabular}

able cardioverter defibrillator was placed in 1 . The median intensive care unit stay was 2 days (range, 2-12 days), and the median hospital stay was 6 days (range, 2-14 days). There were no documented thromboembolic events.

\section{Reoperation}

In 1 patient, mitral valve repair was unsuccessful, the repair was abandoned, and the valve was replaced at the initial operation. He has done well and was in NYHA class I at follow-up. Two of the remaining 38 patients have undergone reoperation. In 1 of these 2 patients, the annuloplasty ring dehisced, resulting in severe mitral incompetence and recurrence of symptoms 4 months after valvuloplasty. This patient had subsequent mitral valve replacement and was in functional class I at follow-up. The second patient experienced recurrence of symptoms and severe mitral regurgitation 3 months after valvuloplasty. An intact neochordal repair was found at reoperation, but there was native chordal rupture and flail at an adjacent valve segment that had been normal at the primary operation. This patient also underwent mitral valve replacement and was in functional class I at follow-up.

\section{Follow-up Echocardiograms}

The degree of mitral regurgitation at echocardiographic follow-up is shown in Figure 3. Three patients who underwent valve replacement are not included in the follow-up portion of Figure 3. Of the remaining 36 patients, 33 (92\%) had mild or less regurgitation, and $3(8 \%)$ had moderate regurgitation. One of these 3 patients is asymptomatic and in NYHA functional class I, and 1 is in class II. The third patient had significant coronary disease. He did well after his combined mitral valve repair and coronary revascularization and was in functional class I with trace mitral regurgitation at 20 months after surgery. Subsequently, he experienced aspiration pneumonitis and sepsis after a lobec- tomy for lung cancer and now has moderate mitral regurgitation. All 36 patients had a morphologically intact valve repair on 2-dimensional echocardiogram, with echocardiographic regurgitation (when present) due to small eccentric jets on Doppler analysis.

\section{Functional Status}

NYHA functional classification for all patients before surgery and at follow-up is presented in Figure 2. The 1 patient in functional class IV is now debilitated after lobectomy complicated by aspiration and sepsis. The patient in functional class III had severe coronary artery disease; she had a competent mitral valve without regurgitation on echocardiogram but had significant left ventricular dysfunction. The patient in functional class II had moderate mitral regurgitation on echocardiogram, had normal ventricular function, and improved relative to preoperative status.

\section{Discussion}

Myxomatous degeneration of the mitral valve is a common etiology for surgically significant mitral regurgitation. Prolapse or flail of the posterior middle scallop is the most common cause of valvular incompetence. ${ }^{1-4}$ Repair for posterior leaflet failure traditionally consists of quadrangular resection, annuloplasty ring placement, and possible sliding annuloplasty. ${ }^{3-8,10,13,15,18,20}$ This classic approach to valve repair can be complex and requires the removal of valve tissue. Recent reports have suggested that similar results can be obtained without resection and sacrifice of potentially valuable leaflet tissue. ${ }^{4,21,22}$ Placement of anterior leaflet neochordae is an accepted method of recreating valve competence for anterior leaflet prolapse, ${ }^{4,12,14}$ and neochordae have been used to repair bileaflet and posterior leaflet prolapse. ${ }^{4,12,14,21,22}$ Investigators have reported excellent longterm durability for repairs with ePTFE neochordae. ${ }^{19,23}$ However, no prior study has focused on the repair of posterior leaflet prolapse (or flail) by placement of neochordae and without leaflet resection.

We believe that neochordal repair for posterior leaflet prolapse offers several advantages over traditional repair techniques. It requires relatively few steps and is expeditiously completed. These attributes are especially advantageous when applied to valve repair with a minimally invasive or robotic approach. Chordal preservation is an 
important goal for mitral operation because it provides for coordinated and optimal function of the left ventricle and the mitral mechanism. ${ }^{11,24-28}$ We believe that chordal reconstruction of the posterior leaflet restores anatomic and dynamic relationships, which may be jeopardized by resection of leaflet tissue, and that reconstruction without resection allows for a physiologic distribution of forces and stress on valve components and the left ventricle. These combined effects could minimize negative effects on cardiac function after valvuloplasty and maximally preserve all potential contributions to cardiac function.

Neochordal repair of the posterior leaflet is a versatile technique, which was readily and successfully applied via open, minimally invasive, and robotic approaches. Median crossclamp and perfusion times are consistently shorter (Table 1) than those reported by Chitwood and associates ${ }^{29}$ for robotic mitral repair (crossclamp, 126 minutes; perfusion, 168 minutes) and by Mohty and colleagues ${ }^{3}$ for open valvuloplasty (perfusion, 86 minutes).

Most series of mitral valve repairs have low operative $(<2 \%)$ and long-term mortality rates. ${ }^{3-8,10,13,15,18,20}$ Perioperative and late deaths are usually due to cardiac failure. ${ }^{4,5,13,18}$ Myocardial failure was responsible for 3 perioperative deaths reported in the series by Gillinov and associates ${ }^{18}$; in 2 of these, a return to bypass was required to fix residual regurgitation, implicating the detrimental effects of prolonged clamp and myocardial ischemic times. In our initial experience with neochordal repair, there have been no perioperative deaths, no prolonged intensive care unit stays, and no mortalities. The potential advantages of neochordal repair include simplicity and maximal conservation of valve tissue, which limit both bypass time and ventricular dysfunction. These factors may have salutary effects on cardiac function, perioperative mortality, and long-term survival after mitral valve repair.

Rates for reoperation and death have been the focal point for many reports of follow-up after mitral valvuloplasty, ${ }^{3,5,18}$ but postoperative functional status has not been consistently described. In a review of their experience with mitral valve repair for myxomatous disease, David and colleagues $^{13}$ reported that most patients were in NYHA functional class I, and in a subsequent report, the classification was $66 \%$ in class I, $26 \%$ in class II, and $7 \%$ in class IV. ${ }^{4} \mathrm{Xu}$ and associates ${ }^{30}$ reported that $96 \%$ of patients were in class I or II after mitral valve repair. Predictors for postoperative cardiac function (congestive heart failure) after surgical correction of mitral regurgitation were preoperative ejection fraction, the presence of coronary artery disease, and preoperative NYHA classification. ${ }^{17} \mathrm{Few}$ of these preoperative risk factors were present in our patient population, and at follow-up, 92\% (33/36) of neochordal repair patients were in functional class I, and 94\% (34/36) were in class I or II. All patients who had valve replacement were in functional class I. The 2 patients in functional class III and IV at follow-up both had multivessel coronary artery disease. One patient had a reduced ejection fraction and had coronary artery bypass operation before her combined redo revascularization and valve repair. This patient has significant left ventricular dysfunction, has no mitral regurgitation, and is in NYHA class III. The patient in class IV has normal left ventricular function but is debilitated after complications after lobectomy for lung cancer. Before this, he was in functional class I at 20 months of follow-up.

Few reports have presented complete echocardiographic follow-up for patients after mitral valve repair. ${ }^{3-5,13,18} \mathrm{Re}-$ view of available reports indicates that mitral regurgitation is present on Doppler echocardiogram in a significant portion of patients after mitral valvuloplasty, with moderate or greater regurgitation in $8 \%$ to $29 \%$ of patients and trace to mild regurgitation in $19 \%$ to $67 \% .^{5,19,20,30}$ In our series, follow-up 2-dimensional mode echocardiography demonstrated an intact repair with good leaflet apposition and no prolapse for 35 of the 36 patients (who did not have valve replacement). In these patients, Doppler analysis revealed no to mild regurgitation in 33 patients and moderate regurgitation in 3 . When present, mitral regurgitation was almost always due to small eccentric jets (2-5 mm wide), and these are of unknown clinical significance. In 1 patient, 2-dimensional echocardiogram demonstrated a morphologically intact repair with mild prolapse of the anterior leaflet and moderate regurgitation on Doppler analysis.

Freedom from reoperation after mitral repair is $85 \%$ to $95 \% \cdot{ }^{3-20}$ Longer follow-up is associated with an increased need for reoperation. ${ }^{3}$ In the series reported by Gillinov and associates, ${ }^{18} 40 \%$ to $50 \%$ of reoperations occurred within 1 year of valve repair, and the remainder occurred over longterm follow-up. In a review of reoperation for failed valvuloplasty, the median time between operations was 2.4 years and ranged from 2 months to 25.3 years. ${ }^{9}$ In our series, mitral valve repair was abandoned in 1 patient because of irreparable anatomy. Two patients $(5 \%)$ who initially had successful repairs required reoperation within 6 months of the original operation. In 1 patient of the 2 , the annuloplasty ring dehisced, and the other had a newly ruptured native chorda. Both of these mechanisms of valvuloplasty failure have been reported and are accepted (and significant) etiologies for early recurrence of regurgitation after valve repair. ${ }^{9}$ Early results for reoperation in our series compare favorably to results for more technically complex repairs.

In conclusion, myxomatous mitral regurgitation due to posterior leaflet prolapse can be repaired by placement of neochordae and an annuloplasty ring. This repair method avoids leaflet resection, allows maximal conservation of valve tissue, and is readily accomplished by traditional and minimally invasive approaches. 


\section{References}

1. Otto CM. Clinical practice. Evaluation and management of chronic mitral regurgitation. $N$ Engl J Med. 2001;345:740-6.

2. Pellerin D, Brecker S, Veyrat C. Degenerative mitral valve disease with emphasis on mitral valve prolapse. Heart (England). 2002; 88(suppl 4):iv20-8.

3. Mohty D, Orszulak TA, Schaff HV, Avierinos JF, Tajik JA, EnriquezSarano M. Very long-term survival and durability of mitral valve repair for mitral valve prolapse. Circulation. 2001;104:I1-7.

4. David TE, Omran A, Armstrong S, Sun Z, Ivanov J. Long-term results of mitral valve repair for myxomatous disease with and without chordal replacement with expanded polytetrafluoroethylene sutures. J Thorac Cardiovasc Surg. 1998;115:1279-85.

5. Braunberger E, Deloche A, Berrebi A, Abdallah F, Celestin JA, Meimoun P, et al. Very long-term results (more than 20 years) of valve repair with carpentier's techniques in nonrheumatic mitral valve insufficiency. Circulation. 2001;104:I8-11.

6. Carpentier A, Deloche A, Dauptain J, Soyer R, Blondeau P, Piwnica $\mathrm{A}$, et al. A new reconstructive operation for correction of mitral and tricuspid insufficiency. J Thorac Cardiovasc Surg. 1971;61:1-13.

7. Carpentier A, Relland J, Deloche A, Fabiani JN, D'Allaines C, Blondeau $\mathrm{P}$, et al. Conservative management of the prolapsed mitral valve. Ann Thorac Surg. 1978;26:294-302.

8. Carpentier A. Cardiac valve surgery-the "French correction." J Thorac Cardiovasc Surg. 1983;86:323-37.

9. Cerfolio RJ, Orszulak TA, Pluth JR, Harmsen WS, Schaff HV. Reoperation after valve repair for mitral regurgitation: early and intermediate results. J Thorac Cardiovasc Surg. 1996;111:1177-83.

10. Cohn LH, Gillinov AM, Scott ML, David TE, Deac RC. Durability of mitral valve repair for degenerative disease: discussion. $J$ Thorac Cardiovasc Surg. 1998;116:742-3.

11. David TE, Uden DE, Strauss HD. The importance of the mitral apparatus in left-ventricular function after correction of mitral regurgitation. Circulation. 1983;68:76-82.

12. David TE, Bos J, Rakowski H. Mitral valve repair by replacement of chordae tendineae with polytetrafluoroethylene sutures. J Thorac Cardiovasc Surg. 1991;101:495-501.

13. David TE, Armstrong S, Sun Z, Daniel L. Late results of mitral-valve repair for mitral regurgitation due to degenerative disease. Ann Thorac Surg. 1993;56:7-14.

14. David TE, Armstrong S, Sun Z. Replacement of chordae tendineae with Gore-Tex sutures: a ten-year experience. J Heart Valve Dis. 1996;5:352-5.

15. Deloche A, Jebara VA, Relland JY, Chauvaud S, Fabiani JN, Perier P, et al. Valve repair with Carpentier techniques. The second decade. J Thorac Cardiovasc Surg. 1990;99:990-1001.

16. Dore A, Sauve C, Amyot R, Lebeau R, Klein M, Cossette R. Mitral valve repair: intermediate to long term echocardiographic follow-up. Can J Cardiol. 1998;14:931-4.

17. Enriquez-Sarano M, Schaff HV, Orszulak TA, Bailey KR, Tajik AJ, Frye RL. Congestive heart failure after surgical correction of mitral regurgitation. A long-term study. Circulation. 1995;92:2496-503.

18. Gillinov AM, Cosgrove DM, Blackstone EH, Diaz R, Arnold JH, Lytle BW, et al. Durability of mitral valve repair for degenerative disease. J Thorac Cardiovasc Surg. 1998;116:734-42.

19. Lim E, Ali ZA, Barlow CW, Hosseinpour AR, Wisbey C, Charman $\mathrm{SC}$, et al. Determinants and assessment of regurgitation after mitral valve repair. J Thorac Cardiovasc Surg. 2002;124:911-7.

20. Nagy ZL, Bodi A, Vaszily M, Szerafin T, Horvath A, Peterffy A Five-year experience with a suture annuloplasty for mitral valve repair. Scand Cardiovasc J. 2000;34:528-32.

21. Duebener LF, Wendler O, Nikoloudakis N, Georg T, Fries R, Schafers HJ. Mitral-valve repair without annuloplasty rings: results after repair of anterior leaflet versus posterior-leaflet defects using polytetrafluoroethylene sutures for chordal replacement. Eur J Cardiothorac Surg. 2000;17:206-12.

22. Lawrie GM, Earle NR, Earle EA. Influence of surgical technique on outcome of mitral valve repair: "the American correction." The Society of Thoracic Surgeons 39th Annual Meeting 2003 Program, 200201. 2003.

23. David T, Ivanov J, Armstrong S, Rakowski H. Late outcomes of mitral valve repair for floppy valves: implications for asymptomatic patients. J Thorac Cardiovasc Surg. 2003;125:1143-52.

24. Moon MR, DeAnda A Jr, Daughters GT, Ingels NB Jr, Miller DC. Experimental evaluation of different chordal preservation methods during mitral valve replacement. Ann Thorac Surg. 1994;58:931-43.

25. Moon MR, DeAnda A Jr, Daughters GT, Ingels NB, Miller DC. Effects of chordal disruption on regional left ventricular torsional deformation. Circulation. 1996;94:II143-51.

26. Sintek CF, Pfeffer TA, Kochamba G, Fletcher A, Khonsari S. Preservation of normal left ventricular geometry during mitral valve replacement. J Heart Valve Dis. 1995;4:471-5.

27. Yun KL, Sintek CF, Miller DC, Schuyler GT, Fletcher AD, Pfeffer TA, et al. Randomized trial of partial versus complete chordal preservation methods of mitral valve replacement: a preliminary report. Circulation. 1999;100:II90-4.

28. Yun KL, Sintek CF, Miller DC, Pfeffer TA, Kochamba GS, Khonsari $\mathrm{S}$, et al. Randomized trial comparing partial versus complete chordalsparing mitral valve replacement: effects on left ventricular volume and function. $J$ Thorac Cardiovasc Surg. 2002;123:707-14.

29. Chitwood WR, Nifong LW, Argenziano M, Smith C, Multi-center Robotic Mitral Repair Group, Greenville N, New York, NY. Multicenter robotic mitral valve repair trial with the da Vinci system. Program Book for the 83rd Annual Meeting of The American Association for Thoracic Surgery, May 2003, 248. 2003.

30. Xu M, Mchaffie DJ, Hilless AD. Mitral valve repair: a clinical and echocardiographic study. Br Heart J. 1994;71:51-6.

\section{Discussion}

Dr Gabriel Aldea (Seattle, Wash). In the past 15 years, techniques for neochordal replacement with ePTFE were introduced by Drs Frater, David, Schaff, and others. These techniques significantly increased the likelihood of repair for myxomatous mitral valve pathology and were demonstrated to have excellent long-term (10-year) durability, which is superior to chordal shortening and transfer. Expanded PTFE chordal replacement had been applied primarily to anterior or mixed anterior posterior leaflet prolapse, but even in Dr David's series from 1997, 15\% of all patients with isolated posterior leaflet prolapse were treated this way. Dr David's criteria for using chordal replacement with ePTFE over the traditional quadrangular resection or reconstruction with ring annuloplasty were quite specific and included extensive resection of $\mathrm{P} 2$ (which included a resection of more than a third of the posterior leaflet or $>1.5 \mathrm{~cm}$ ), multiple elongated P2 chords, or paracommissural posterior leaflet pathology. He specifically cautioned that extensive P2 resection needed to be accompanied by a Carpentier ring annuloplasty to prevent both systolic anterior motion and posterior wall motion abnormality. The University of Southern California team under Dr Vaughn Starnes' leadership has logically expanded the concept of neochordal repair to leaflet preservation routinely to patients with isolated posterior chord prolapse. They reported an initial experience with 39 patients with complete but relatively short follow-up, with a median follow-up of 1 year. Their results are excellent, with $0 \%$ mortality, excellent relief of symptoms, and echocardiographic confirmation of minimal to no mitral regurgitation in $92 \%$ of the patients, confirming that this approach in fact is both effective and successful. Three patients, however, required mitral valve replacement, as we have seen: 1 in the operating room and 2 within 4 months of surgery, 1 again for an annuloplasty ring dehiscence, and another for a new ruptured adjacent native chord pathology.

I have several questions for the authors. Do these 39 consecutive patients treated over a 20 -year period of time represent the entire mitral valve repair population for posterior or mixed poste- 
rior anterior pathology, or is this a selected subset of patients, and, if so, how were these patients selected?

Dr Nigro. We have made a commitment to attempt repair of the posterior leaflet prolapse patients in this manner and this represents the bulk of those patients. Since January of 2000 the senior author has adopted neochordal reconstruction as his preferred valvuloplasty technique for posterior leaflet prolapse or flail due to myxomatous degeneration. During the study period he performed no repairs using leaflet resection for this valve pathology. Other surgeons at this institution may have continued to use traditional valvuloplasty methods; however the majority of patients with myxomatous posterior leaflet prolapse (at this center) underwent valve repair by the senior author with the neochordal technique. This series represents the bulk of patients with (repairable) regurgitation due to myxomatous degeneration and prolapse or flail of the posterior mitral leaflet that underwent valvuloplasty at this center during the study period.

Patient selection was as stated in the paper: 39 consecutive adult patients with significant (severe) mitral regurgitation due to myxomatous mitral degeneration and prolapse or flail of the posterior mitral leaflet, and who met the traditional criterion for mitral valvuloplasty.

Our center completes roughly 100 to 200 adult mitral valve operations per year. Due to our patient demographics, an unusually large percentage (relative to most of North America) has rheumatic, congenital, or infective etiologies of mitral disease. Neochordal reconstruction for isolated anterior leaflet prolapse is an accepted and proven repair method; patients with this pathology have been excluded to provide for a focused review of posterior leaflet repair. Because of these factors and our desire to focus (this study) on adult patients undergoing initial repair for myxomatous posterior leaflet disease, the study group consists of 39 consecutive patients acquired in roughly 2 to 3 years.

Dr Aldea. Most of us are reasonably satisfied with the French correction, that is, the quadrangular resection reconstruction with ring annuloplasty, and are aware that $10 \%$ of patients treated that way will present with reoperation and typically with a flail because of a new rupture of an adjacent chord, and typically $50 \%$ of those failures occur early. Was your motivation for moving to this repair caused by dissatisfaction with long-term outcomes or by the newer restrictions introduced by minimally invasive approaches?

Dr Nigro. The answer to that question is that it was influenced by both issues. Decades of research and clinical work have consistently indicated that maximal conservation of valvular and subvalvular apparatus is critical for optimal valve and ventricular function and to minimize valvuloplasty morbidity and mortality. We were clearly motivated by the combined desires to develop a valvuloplasty technique that provides for valvular competence, optimizes cardiac/ventricular function, limits bypass time, and facilitates minimally invasive techniques.

Dr Aldea. My next question is a somewhat technical one. Although Dr Starnes makes it look easy, how difficult is it to assess the proper height of repair for these neochords, and when you preserve the entire posterior leaflet, do you make any adjustment for the size of the annuloplasty ring that is implanted? From your manuscript, the mean size of the annuloplasty ring is 30 , so I assume that there is no correction or no change in the way you normally or previously sized the annuloplasty ring.

Dr Nigro. Adjustment of chordal length is critical for the successful application of this valvuloplasty technique; it is accomplished based on the adjacent normal chordae and to provide for optimal leaflet coaption at or below the level of the annulus. It is an acquired skill that requires significant knowledge of and experience with mitral valvuloplasty techniques.

A flexible partial ring was utilized and sized based on the anterior leaflet as has been widely advocated for mitral valvuloplasty. We believe that the neochordal repair technique minimizes the risk of SAM because valvular restructuring is avoided and a flexible annuloplasty ring is used.

Dr Aldea. The reason why I asked the question is that we know from finite element analysis, for example, from Dr Kunstleman's work, that although you can achieve competence with chords being just the right length or slightly longer, tension on adjacent chords may vary quite a bit, and perhaps that is the explanation for one of the delayed chordal ruptures that was seen.

Finally, do the authors believe that the early failure rate of $5 \%$ will be significantly reduced with increasing experience or with more specific indications for this?

Dr Nigro. You know it is possible that the failure rate will be reduced with more experience; but the failures may prove to be independent of repair type. The first patient, who underwent replacement intraoperatively, represents an attempt to repair a very dysmorphic valve. And it was unsuccessful. I think these things happen in most series and maybe are not included in the results. The other 2 patients are interesting because they represent failures within the first year due to widely known failure mechanisms. Annuloplasty ring dehiscence was present in roughly half of the early failures in the Mayo series clinic review of open valvuloplasty failures, and chordal rupture was apparent in that group as well in roughly the same percentage. Now only time will tell. It's not surprising that repairs break down early just like they have in other series and hopefully in a follow-up study we will be able to tell you what happens over the long term. Roughly $50 \%$ of failures happened in the first year in both the Cleveland Clinic series and the Mayo series and the remaining happened over time, so time will tell.

Dr Aldea. And finally, in the evolution of the American repair from our French roots, do you see any circumstances in which a ring annuloplasty would not be necessary?

Dr Nigro. You know the literature suggests most experienced valve surgeons are committed to a ring annuloplasty. I believe anything is possible but I think at this point a ring annuloplasty is an integral part of repair. You bring up an interesting point. I think that the Texas group has recently published a series called "The American Correction" in which they have performed most of their recent valve repairs without leaflet resection, so this is a very interesting topic. 